\title{
Impact analysis of input parameter for damage detection code
}

\author{
Michal Venglar ${ }^{1, *}$ and Milan Sokol ${ }^{1}$ \\ ${ }^{1}$ Slovak University of Technology in Bratislava, Faculty of Civil Engineering, Department of \\ Structural Mechanics, Radlinskeho 11, 81005, Bratislava, Slovakia
}

\begin{abstract}
The primary aim of the article is to analyse impact of appropriate values of input parameter for an effective solution of the self-developed code used for damage detection. The code was prepared to determine the change of bending stiffness in Microsoft Office Excel Visual Basic for Applications. The code used non-destructive vibration based method, i.e. the FE model updating method. A steel bar was assumed for numerical calculation. Time consumption of calculation, precision of identification and degree of possible damage detection were investigated. The values of computation time depend on the input values, the desired limit of the accepted error. Then, data from a laboratory experiment was analysed. The damage detection was done in accordance with the suitable input data from a parametric study of the steel bar.
\end{abstract}

\section{Introduction}

Nowadays, damage detection gets ahead throughout the civil, mechanical and aerospace engineering communities [1-3]. For civil engineers, it is caused by increasing demands on safety and reduction of maintenance cost [4-5]. Another reason is that many bridges are obsolete and need for their rehabilitation [6]. In accordance with [7], the average age of bridges in Slovakia is over 43 years. In many cases, lack of long-lasting maintenance or periodic inspection may result in necessity of later expensive complete reconstruction or construction of a new bridge structure which is often even more expansive. The circumstance from the USA confirms this fact. The 94-year-old Greenfield Bridge in Pittsburgh had to be demolished in 2005 and a new structure have replaced the old one. Structural health monitoring can help us to avoid above-mentioned situations.

Many methods are used for monitoring of structures e.g. visual controls, destructive methods, non-destructive methods. The Finite Element Model Updating (FEMU) method is one of vibration based non-destructive methods. Several approaches of FEMU method were summarized in [8-9]. The FEMU method is also applied to damage detection with neglecting damping of structure in a simple self-developed code. The used version of the code has been customized in comparison to its published version in [10]. The paper is devoted to analysis of input data and their impact on accuracy of damage assessment and analysis of minimum

${ }^{*}$ Corresponding author: michal.venglar@stuba.sk 
degree of possible damage that can be detect on a numerical model of a steel bar. The achieved date will be used for system identification of an experimental laboratory specimen.

\section{Study of input parameter LIMIT}

The theory and description of the code was described in [10]. However, it has been modified a little bit for this study. The self-developed code in Excel VBA uses more input parameters, which affect the accuracy of the results and the time consumption of calculations. The modal analysis of the steel beam was done in the FEM software and the results were used as the input data for calculations. Specified changes of stiffness were applied for the 35 elements in case of the modal analysis and for damage detection. The length of the used element was 100 $\mathrm{mm}$, so the length of the investigated beam was $3500 \mathrm{~mm}$. The second calculations were prepared in a way that the only one element $(1200 \mathrm{~mm}$ from the right side of the beam) had changed the height of the cross-section (Fig. 1). Damaged scenarios for the one element and appropriate eigen frequencies for the beam are shown in the Fig. 2.

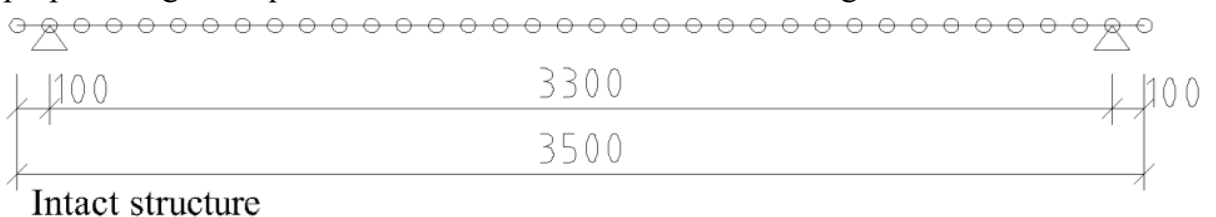

\section{Intact structure}

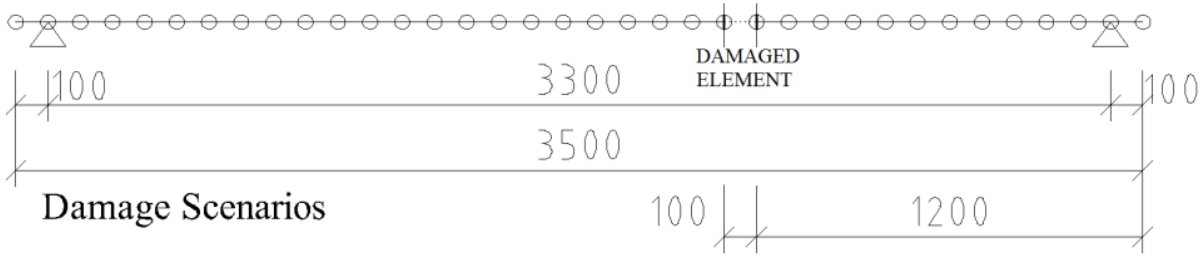

Fig. 1. The investigated steel beam.

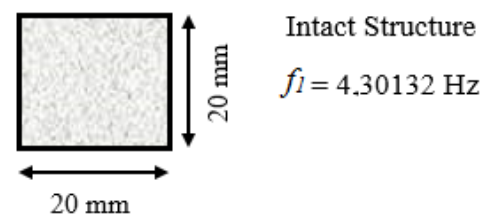

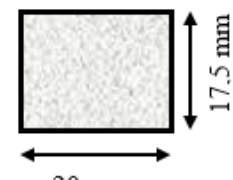

$20 \mathrm{~mm}$

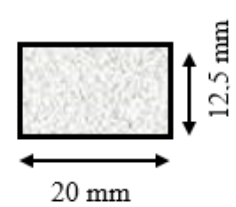

Damaged Structure 1

$f_{l}=4.25154 \mathrm{~Hz}$

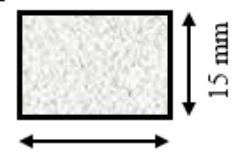

$20 \mathrm{~mm}$

Damaged Structure 3

$f_{l}=4.01280 \mathrm{~Hz}$
Damaged Structure 2

$f_{l}=4.16669 \mathrm{~Hz}$

Damaged Structure 4

$f_{l}=3.71775 \mathrm{~Hz}$

Fig. 2. Damage scenarios and corresponding eigen frequencies of structure. 
The PC used for the calculations consisted of 8-core processor and it worked with 3.25 GB of RAM. The code ran only in the 32-bit operating system.

\subsection{Accuracy and time consumption}

The limit value of auxiliary error (indicated by LIMIT in accordance with [10]) was monitored during this parametric study for the Damage Scenario 4 (Fig. 2). The auxiliary error FAULT equivalents the sum of squares of differences between the desired and calculated displacements at nodes, thus:

$$
F A U L T=\frac{\sum\left(Y_{i}-Y_{-} Y_{i}\right)^{2}}{\sum Y_{i}^{2}} 100 \%
$$

where $Y_{-} Y_{i}$ is the bending mode-shape and $Y_{i}$ is the desired state of the appropriate bending mode-shape (Fig. 3).

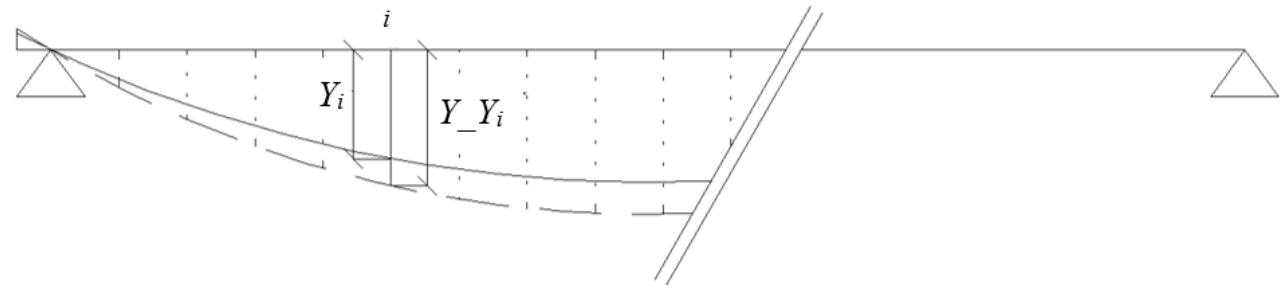

Fig. 3. Description of the code (desired displacement - $Y_{i}$, calculated displacement - $Y_{-} Y_{i}$ ).

The whole calculation runs in a while-loop cycle. The while-loop cycle ends when the FAULT value is smaller than the LIMIT value. This is the only one condition which completes the calculation of damage. During the parametric study seven cases of LIMIT value has been investigated. The LIMIT value was considered in logarithmic scale from $0.5 \%$ to $0.0000005 \%$.

The parametric study gives logical results and it is possible to indicate that time consumption of the calculation is the highest in the case of the LIMIT value - the smallest auxiliary error. Analyses with value of LIMIT from $0.5 \%$ to $0.0005 \%$ are below the needed accuracy and the future application is not recommended. Other calculations exceeded time consumption of 6 minutes. On the other hand, the difference between real and identified stiffness has dropped below difference of $20 \%$. This value can be acceptable. Finally, the difference for the identified stiffness achieved zero when the exact LIMIT value $0.0000005 \%$ was assumed. The calculated difference is negligible in this case. However, the computation time has increased approximately up to 2 hours.

Based on the above-mentioned, it can be concluded that the optimum ratio of time consumption and the minimal difference has been reached for the LIMIT value which is about $0.000005 \%$. This parameter was also used in the next chapters of the paper.

\subsection{Degree of damage detection}

Damage of structure can assume various proportions. Big damages could be very dangerous and it is possible to identify them. On the other hand, smaller damages should also be identified. Four damage scenarios were considered. In accordance with the Fig. 1, the height of damaged element has been gradually changing. The height was assumed between 10 and $20 \mathrm{~mm}$.

The appropriate LIMIT value was used for damage detection in the mentioned scenarios. For calculating the difference in the damage detection, the following formula was used: 


$$
\text { Difference }=\frac{(A-B)}{\max (A, B)} 100 \%
$$

where A is the identified bending stiffness and B the desired (real) bending stiffness. The Table 1 shows that various damages could be detect by the developed code. The small change in height (Damaged structure 1) can also be detected. The difference in detection is approximately $19 \%$.

Table 1. Comparison of damage detection for more scenarios.

\begin{tabular}{|c|c|c|c|c|}
\hline $\begin{array}{c}\text { Damage } \\
\text { scenario }\end{array}$ & $\begin{array}{c}\text { Identified } \\
\text { stiffness } \boldsymbol{E I} \\
{\left[\mathbf{N m}^{2}\right]}\end{array}$ & $\begin{array}{c}\text { Real stiffness } \\
\boldsymbol{E} \boldsymbol{[}\left[\mathbf{N m}^{2}\right]\end{array}$ & $\begin{array}{c}\text { Difference } \\
{[\%]}\end{array}$ & $\begin{array}{c}\text { Time } \\
\text { consumption }\end{array}$ \\
\hline Intact & 2791.98 & 2793.00 & -0 & 1 min $24 \mathrm{~s}$ \\
\hline Damaged 1 & 2328.30 & 1875.78 & +19 & $4 \min 25 \mathrm{~s}$ \\
\hline Damaged 2 & 1179.12 & 1459.25 & +19 & $13 \min 51 \mathrm{~s}$ \\
\hline Damaged 3 & 733.60 & 683.59 & +7 & $22 \min 9 \mathrm{~s}$ \\
\hline Damaged 4 & 365.14 & 351.00 & +4 & $27 \min 42 \mathrm{~s}$ \\
\hline
\end{tabular}

\section{System identification of experimental laboratory model}

The application of above-mentioned system identification was conducted in different case than in study of input parameter. The investigated experimental laboratory model was made from wooden and plaster boards. Three wooden boards were used for the main beam and the deck was made of the 3 plasterboard layers with height of $12.5 \mathrm{~mm}$. The deck was $300 \mathrm{~mm}$ wide and $37.5 \mathrm{~mm}$ high in total. The composite beam was 4 metres long and it was supported as the simple supported beam with a single span of 3.9 metres.

Firstly, data for solid model were acquired. Secondly, a stiffener on the main beam was added for simpler modelling of the stiffness change (damage). The stiffener was also located $1200 \mathrm{~mm}$ from the right side of the specimen but its length was $200 \mathrm{~mm}$. The real bending stiffness $E I$ with the stiffener was $375 \mathrm{kNm}^{2}$. Acceleration was measured at 18 points along the experimental specimen, so the stiffener represented one half of the distance between placed accelerometers. Analyses of the measurement data (in accordance with [11]) were used for identifying of the first vertical mode-shape.

Using optimized parameters, the more satisfactory degree of the accuracy of the damage detection was achieved in comparison with unoptimized input parameter. The difference in the identified stiffness was reduced (Table 2). The optimized input value of the parameter LIMIT gave more accurate results, but the damage assessment was not good enough. On the other hand, the difference about $19 \%$ is still acceptable.

Table 2. Identification of stiffener in self-developed code.

\begin{tabular}{|c|c|c|}
\hline Method & $\begin{array}{c}\text { Identified stiffness } \\
\boldsymbol{E}\left[\mathbf{[} \mathbf{k N m}^{2}\right]\end{array}$ & Difference [\%] \\
\hline $\begin{array}{c}\text { FEMU } \\
\text { (unoptimized) }\end{array}$ & 247 & -34 \\
\hline FEMU (optimized) & 314 & -19 \\
\hline
\end{tabular}




\section{Conclusions}

The parametric study verified the time consumption of calculations, as well as the desired accuracy of the damage assessment. The difference between calculated and desired displacement was minimized and the results were accurately determined. The identification of the stiffness was successful with acceptable differences in above-mentioned parameter by using the sufficiently small LIMIT value. The price for the high accuracy of the assessment was enormous time-consumption. It appears to be reasonable (the ratio between accuracy and time-consumption) to use the optimized value of accuracy.

The various damage scenarios were investigated. The code could find quite small damage like the reduced height of the cross-section. The smallest investigated reduction was about $10 \%$ of the total height.

The LIMIT value which had been found in the parametric study was applied for the damage detection (in this case the addition of the stiffener), which was carried out on the experimental laboratory model. The achieved results of the damage detection were better than with unoptimized parameter. The location of the damage has been properly identified, as well as the value of the identified stiffness which was closer to the exact value.

This paper has been supported by the Slovak Research and Development Agency (SRDA), i.e. a grant from research program No. APVV-0236-12.

\section{References}

1. G. Pandey, E.T. Thostenson, D. Heider, Progr. Electromagn. Res. 137, 551 (2013)

2. M. Radzienski, Ł. Dolinski, M. Krawczuk, M. Palacz, Mech. Syst. Sig. Process. 39, 388 (2013)

3. J. Niu, Z. Zong, F. Chu, Sci. Chin. Technol. Sci. 58, 701 (2015)

4. H. Wenzel, D. Pichler, Ambient Vibration Monitoring (John Wiley \& Sons, Ltd, Chichester, 2005)

5. H. Wenzel, Health Monitoring of Bridges (John Wiley \& Sons, Ltd, Chichester, 2009)

6. P. Franchetti, M. Frizzarin, A. Leonardi, F. Zeni, MATEC Web of Conferences 24, 09008 (2015)

7. P. Paulik, Bridges in Slovakia (Jaga, Bratislava, 2014)

8. E.P. Carden, P. Fanning, Struct. Health Monit. 3, 355 (2004)

9. T. Marwala, Finite-Element-Model Updating Using Computational Intelligence Techniques: Application to Structural Dynamics (Springer, London, 2010)

10. M. Sokol, R. Aroch, M. Venglar, M. Fabry, T. Zivner, Appl. Mech. and Mat. 769, 192 (2015)

11. M. Sokol, R. Flesch, J. Bridge Eng. 10, 77 (2010) 